\title{
Fracasso escolar e evasão no Ensino Médio no Brasil: estado do conhecimento
}

\section{School failure and evasion in High School in Brazil: state of knowledge \\ Fracaso y evasión escolar en la Escuela Secundaria en Brasil: estado del conocimiento}

João Carlos de Souza Nascimento1; Edileuza Knupp Nascimento'; Daniela Beatriz Pires Camargo ${ }^{1}$; Tiago Esteves da Silva ${ }^{1}$; Tiago Dias Ferracioli Azevedo ${ }^{1}$; Carolina Ferreira Barros Klumpp ${ }^{1}$

\section{RESUMO}

A presente pesquisa teve como objetivo principal realizar uma revisão (estado do conhecimento) sobre a evasão escolar no Ensino Médio no Brasil, tendo como ênfase o fracasso escolar, de modo a compreender as principais variáveis e aspectos relacionados ao abandono por parte dos alunos deste ciclo na formação básica da escolarização. Foram selecionados artigos nacionais da base de dados Capes Periódicos considerando a última década, utilizando a combinação dos descritores "evasão escolar" e "ensino médio". Os dados coletados foram submetidos à análise de conteúdo. Os resultados principais evidenciaram que a evasão escolar ocorre, na maioria das vezes, por causa da vulnerabilidade social, falta de adequação das propostas pedagógicas à realidade dos estudantes, ausência de políticas públicas e trabalho precoce.

Palavras-chave: Ensino-aprendizagem; Abandono escolar; Jovens.

\begin{abstract}
The main objective of this research was to carry out a review (state of knowledge) on school dropout in high school in Brazil, with an emphasis on school failure, in order to understand the main variables and aspects related to dropout by students in this cycle in basic education schooling. National articles were selected from the Capes Periódicos database considering the last decade, using the combination of the descriptors "school dropout" and "high school". The collected data were submitted to content analysis. The main results showed that school dropout occurs, most of the time, because of social vulnerability, lack of adequacy of pedagogical proposals to the reality of students, absence of public policies and early work.
\end{abstract}

Keywords: Teaching-learning; School dropout; Young.

\section{RESUMEN}

El objetivo principal de esta investigación fue llevar a cabo una revisión (estado del conociemento) sobre el abandono escolar en la escuela secundaria en Brasil, con énfasis en el fracaso escolar, con el fin de comprender las principales variables y aspectos relacionados con el abandono escolar de los estudiantes en este ciclo de educación básica. enseñanza. Se seleccionaron artículos nacionales de la base de datos de Capes Periódicos considerando la última década, utilizando la combinación de los descriptores "deserción escolar" y "escuela

\footnotetext{
${ }^{1}$ UNIB - Universidade Ibirapuera, São Paulo/SP - Brasil.
} 
secundaria". Los datos recopilados fueron sometidos a análisis de contenido. Los principales resultados mostraron que la deserción escolar ocurre, la mayoría de las veces, debido a la vulnerabilidad social, la falta de adecuación de las propuestas pedagógicas a la realidad de los estudiantes, la ausencia de políticas públicas y el trabajo temprano.

Palabras clave: Enseñanza-aprendizaje; Abandono de escuela; Joven.

\section{INTRODUÇÃO}

A discussão sobre o fracasso escolar é antiga e cada vez mais relevante, porém, apesar dos vários debates, o que mais se observa é a procura por um culpado ou uma solução mágica para sua dissolução, como se isto fosse possível. Mas será que existe realmente um "culpado" para esta situação? É possível solucionar este problema baseando-se em uma única causa? Pois bem, vivemos em uma sociedade que nos leva a procurar culpados para tudo, mas se tratando desta problemática, não é possível se basear em uma única causa, ou procurar alguém para colocar a culpa, pois, como veremos no decorrer deste estudo, notaremos que são muitas as variáveis encontradas para explicar este fenômeno, bem como para associá-lo à evasão escolar.

Quando falamos de fracasso escolar estamos abordando um problema estrutural que deve ser observado sob um prisma sócio-histórico. Tratar sobre o fracasso escolar é compreender que no processo de aprendizagem do aluno não existe uma fórmula mágica do sucesso, como tampouco existe uma única causa que desencadeie o insucesso. Estamos discorrendo também acerca das condições dos alunos tanto cognitivas quanto psicológicas, físicas, familiares e sociais; de problemas de estrutura escolar, além da situação vivida pelos professores, que envolve a má remuneração, a falta de reconhecimento e de condições de trabalho, dentre outros fatores.

Ao abordar a temática do fracasso escolar, é importante determinar as concepções de fracasso existentes na literatura, visto que a forma de se conceber este construto irá determinar quais causas serão consideradas e quais serão excluídas na explicação do fenômeno.

De uma forma mais generalista Faubert (2012) destaca a perspectiva mais convencional, que toma como ponto de vista o fator individual, definindo este fenômeno como o fracasso de um estudante em obter um padrão mínimo necessário determinado por uma idade, um grau, um modelo; e outra que compreende o fracasso escolar como produto de um sistema educacional ineficaz no que se refere ao apoio e assistência adequados a todos os alunos, de modo que todos pudessem alcançar o sucesso utilizando seu potencial acadêmico.

Angelucci (2004), em seu estudo de estado da arte sobre a temática, abrange uma amostragem sobre as pesquisas educacionais na área, em que expõe uma categorização em que este fenômeno é concebido sob a ótica de quatro fatores que explicam o fracasso escolar: 1) como problema psíquico, 2) como um problema técnico; 3) como questão institucional e; 4) como questão política.

Seguindo o raciocínio da autora, em relação ao fracasso escolar como problema psíquico, este fenômeno é entendido como um problema estritamente individual, centrado no aluno, sendo atribuído à sua imaturidade no que se referem às suas dificuldades de aprendizagem. Nesta concepção " $a$ pobreza dos alunos (como fator exterior à escola) é a principal causa do seu insucesso escolar" (ANGELUCCI, 2004, p. 60), cabendo esclarecer que o foco desta perspectiva é "inibição intelectual 
em função de dificuldades emocionais", como mencionado pela autora, devido à desestruturação das relações familiares.

Na perspectiva do fracasso escolar como problema técnico, a responsabilidade pela sua ocorrência está centrada na figura do professor, a quem falta o domínio da técnica para lidar com as adversidades do aprendizado de cada aluno (ANGELUCCI, 2004). Neste cenário, podemos ousar dizer que o processo de ensino-aprendizagem é pautado como um objeto, em que basta a administração da metodologia correta para garantir a formação do aluno.

O terceiro panorama que Angelucci (2004) nos apresenta é o fracasso escolar como questão institucional, que "entende a escola como instituição social que contraditoriamente reproduz e transforma a estrutura social". Deste modo, a escola também está a serviço da produção de desigualdades e da exclusão social, visto que se estrutura como um microcosmo desta sociedade e suas políticas públicas acabam se tornando também um fator determinante na produção do fenômeno, ao mesmo tempo em que aparecem como "tábua de salvação" em que se acredita sua implementação trará as soluções para sua erradicação.

Por fim, Angelucci (2004) traz a vertente do fracasso escolar como questão política, da cultura escolar, cultura popular e relações de poder, em que "o foco, [...], incide nas relações de poder estabelecidas no interior da instituição escolar..." (ANGELUCCI, p.63, 2004), voltada principalmente na violência promovida na escola ao desvalorizar a cultura popular e favorecer a cultura dominante. Lima (2019), em sua pesquisa sobre as origens emocionais da evasão escolar de Educação de Jovens e Adultos, faz-nos refletir sobre uma relação associativa ao fator político, de que a construção etnográfica se dá pela existência de fatores em que o sujeito reúne situações que o politizam a seu desfavor. Pode-se elencar estes fatores como: a existência da topografia social; falta de estrutura econômica familiar; precarização da agência escolar por parte da sociedade e do aluno; evasão escolar causadora de desânimo, cansaço e desfavor ao ensino. Forma-se assim, um fator político que, de certa forma, está engajado em diversas estruturas da instituição escolar e que, se não forem reordenados, oferecem grande perigo aos alunos.

Outra autora que se destaca em relação a este aspecto é Patto (1988), a qual faz uma forte crítica à teoria da Carência Cultural, bastante difundida nos anos 70, que trazia como premissa que as diferenças do ambiente cultural das crianças pobres, por serem menos favorecidos, ocasionavam as dificuldades de aprendizado, portanto, a escola não poderia ensinar esta parcela da população da mesma forma que o fazia para as crianças das "classes favorecidas". Para esta autora a escola é inadequada para alunos pobres, uma vez que métodos de ensino iguais e os mesmos conteúdos estariam falhando com estas crianças, as quais não "culturalmente deficientes ou diferentes". Existe, neste sentido, uma crença no pensamento educacional brasileiro de que os integrantes das classes populares menos favorecidas são lesados do ponto de vista das habilidades perceptivas, motoras, cognitivas (PATTO, 1988).

Cabe-nos também, mencionar a contribuição de Forganiani (2007) que traz, ademais, a teoria críticoreprodutivista de Bourdieu e Passeron, visto que esta coloca em evidência o fator das relações de poder, introduzindo "a possibilidade de se pensar o papel da escola no âmbito de uma concepção crítica de sociedade" (FORGIARINI \& SILVA, 2007, p.9). Evidencia-se o fator social apontado na fala de Bordieu e Passeron, pois este "foi socialmente produzido, num trabalho coletivo de construção da realidade social e por meio desse trabalho" (BOURDIEU, 2000, p. 37). 
Como podemos observar, são muitas as teorias que tratam do fracasso escolar, porém também recorremos a alguns dados estatísticos para que o leitor possa ter uma visão mais completa deste fenômeno, com enfoque na modalidade do Ensino Médio, uma vez que este é o foco de nossa pesquisa, como também um panorama na EJA, para termos melhores condições de refletir sobre o tema.

Sabemos que garantir que os adolescentes brasileiros permaneçam na escola nos anos finais do Ensino Médio é o principal desafio para que o Brasil consiga universalizar o acesso à Educação Básica. Isso porque, de acordo com dados divulgados pelo Instituto Brasileiro de Geografia e Estatística (IBGE), a evasão escolar continua a afetar, sobretudo, jovens na faixa etária dos 15 a 17 anos. De acordo com levantamento realizado no ano de 2019 pelo IBGE, a renda é um dos fatores que determinam os percentuais de abandono e atraso escolar dos jovens desta faixa etária.

Considerando o mesmo perfil, ou seja, alunos na mesma faixa etária e mesmo período letivo, os índices, quando comparados, são discrepantes em relação à classe social. Cerca de $11,8 \%$ dos jovens mais pobres tinham abandonado a escola sem concluir o ensino médio em 2018. Esse percentual é oito vezes maior que o dos jovens mais ricos $(1,4 \%)$. Além das questões relacionadas à classe social, também são fatores que propiciam a evasão escolar a falta de interesse dos alunos, o exagero de conteúdo descontextualizado e até mesmo o bullying.

Os estudantes que abandonam a escola, seja em qual período letivo ou série, terão sérias consequências como a baixa autoestima, sendo esse fator que irá dificultar as relações pessoas e profissionais. Desse modo, o mercado de trabalho acaba ficando mais restrito para esses alunos, pois sem a escolarização existe o comprometimento em relação às exigências básicas de formação a serem cumpridas.

Esse conjunto de fatores acaba por gerar sentimento de desmotivação e isolamento social, consolidando ainda mais a desigualdade social no país. Assim como nas classes de ensino médio, as classes de Ensino para Jovens Adultos (EJA) também têm altos índices de evasão por parte dos alunos. Os educadores das escolas que ofertam essa modalidade de ensino, durante anos têm se perguntado quais os reais motivos que levam esses alunos a abandonarem os estudos. Em alguns casos, o número de alunos que abandonam os estudos é superior ao número de alunos que se formam.

Os alunos do EJA possuem particularidades distintas quando comparados aos alunos do ensino médio. Geralmente são pessoas de baixa renda, que já possuem uma colocação no mercado de trabalho, mas que precisam de qualificação básica. Além disso, caracteriza-se por salas com pessoas de faixas etárias distintas, o que muitas vezes dificulta o processo de ensino-aprendizagem. Neste sentido, a unidade escolar precisa realizar um trabalho de conhecimento de seus alunos que são matriculados no EJA, para traçar um plano de atividades metodológicas a fim de atender as necessidades do todo.

Por fim, é preciso ter claro que o fracasso escolar, juntamente com o fenômeno da evasão escolar, é um grande sintoma e uma construção de toda uma conjuntura histórica e social, e que não existe um culpado, porém é necessário analisar a maneira como ocorre em cada lugar para que se tenha um quadro geral que permita ter ações mais efetivas para atenuá-lo e resolver as questões que estão por detrás de seu contexto, assim como enfatizar o papel da pesquisa no apontamento destes possíveis caminhos.

Deste modo, a presente pesquisa tem como objetivo principal realizar um levantamento do estado de conhecimento sobre a evasão escolar no ensino médio no Brasil, tendo como ênfase o fracasso escolar, de 
modo a compreender as principais variáveis e aspectos relacionados ao abandono por parte dos alunos deste ciclo na formação básica.

\section{MÉTODO}

Para a construção da metodologia desta pesquisa foi realizado um levantamento sobre o estado de conhecimento do tema abordado. De acordo com Morosini (2015) o estado de conhecimento referese à identificação e categorização que culminam na reflexão e síntese sobre a produção científica de uma determinada área, em um determinado espaço de tempo sobre uma temática específica em livros, periódicos, dissertações e teses.

Para a coleta de dados utilizamos como questão norteadora: O que foi discutido no Brasil sobre a evasão escolar no ensino médio na última década? Para responder esta questão buscaram-se em artigos publicados em periódicos científicos indexados no Portal de Periódicos CAPES, com ênfase na combinação dos seguintes descritores, em português: Evasão escolar e Ensino Médio.

Após esta primeira etapa, foi estabelecido critérios para inclusão e exclusão de artigos. Para inclusão utilizaram-se artigos que abordavam a evasão escolar no ensino médio no Brasil, apresentando os descritores no título e/ou resumo e/ou palavras-chave; período de publicação correspondente aos anos de 2008-2019; textos publicados na íntegra e de livre acesso.

Para a análise de dados foi utilizada a análise de conteúdo. De acordo com Bardin (2009) este tipo de análise é um conjunto de técnicas que visa obter, por procedimentos sistemáticos e objetivos de descrição do conteúdo dos textos/mensagens, indicadores que permitem a inferência de conhecimentos relativos ao objeto de estudo.

Os resultados, para uma melhor compreensão, foram sistematizados em tabelas, as quais sumarizam inicialmente informações relevantes sobre os estudos selecionados, caracterizando-os de acordo com ano de publicação, periódico, objetivos e métodos empregados, entre outros dados; e as demais tabelas trazem as principais conclusões sobre os resultados destas pesquisas, bem como as contribuições para a compreensão do fracasso escolar no Ensino Médio.

\section{RESULTADOS DE DISCUSSÃO}

Na Tabela 1 há a descrição do ano de publicação, título, autores e periódicos de publicação dos artigos selecionados. O total de artigos que se enquadraram aos critérios de inclusão foram 10, como sumarizados a seguir.

Tabela 1 - Ano de publicação, título, autores e periódico

\begin{tabular}{|c|c|c|c|c|}
\hline Id & Ano & Título & Autores & Periódico \\
\hline 1 & 2008 & $\begin{array}{l}\text { Preciso estudar para ser } \\
\text { alguém: memórias e } \\
\text { representações sociais da } \\
\text { educação escolar }\end{array}$ & $\begin{array}{c}\text { NAIFF, Luciene, Almeida } \\
\text { Miguel; SÁ, Celso Pereira } \\
\text { de; NAIFF, Denis Giovanni } \\
\text { Monteiro }\end{array}$ & Paidéia (Ribeirão Preto) \\
\hline
\end{tabular}




\begin{tabular}{|c|c|c|c|c|}
\hline 2 & 2008 & $\begin{array}{c}\text { Trabalho precoce e processo } \\
\text { de escolarização de crianças } \\
\text { e adolescentes }\end{array}$ & $\begin{array}{l}\text { SOUSA, Olívia Maria Costa } \\
\text { Grangeiro de; ALBERTO, } \\
\text { Maria de Fátima Pereira }\end{array}$ & $\begin{array}{l}\text { Psicologia em Estudo, Maringá, } \\
\text { v. } 13 \text {, n. } 4 \text {, p. } 713-722 \text {, }\end{array}$ \\
\hline 3 & 2009 & $\begin{array}{c}\text { Fracassos, representações e } \\
\text { exclusões no processo de } \\
\text { permanência na escola }\end{array}$ & $\begin{array}{l}\text { GOMES, Claudia } \\
\text { SOUZA, Vera Lucia } \\
\text { Trevisan de }\end{array}$ & Rev. psicopedag \\
\hline 4 & 2011 & $\begin{array}{l}\text { Da inclusão à evasão } \\
\text { escolar: o papel da } \\
\text { motivação no ensino médio }\end{array}$ & MENDES, Marcelo Somões & $\begin{array}{l}\text { Estudos de Psicologia } \\
\text { (Campinas) }\end{array}$ \\
\hline 5 & 2011 & $\begin{array}{c}\text { A educação, a sublimação e } \\
\text { os ideais }\end{array}$ & $\begin{array}{l}\text { GUIMARÃES,Marisa } \\
\text { Siggelkow }\end{array}$ & $\begin{array}{l}\text { http://www.uva.br/artigos } \\
\text { temáticos }\end{array}$ \\
\hline 6 & 2013 & $\begin{array}{c}\text { Evasão escolar na educação } \\
\text { de jovens e adultos: } \\
\text { problematizando o } \\
\text { fenômeno com enfoque na } \\
\text { cultura escrita. }\end{array}$ & $\begin{array}{c}\text { PEDRALI; RIZZATTTI. } \\
\text { Rosângela; Mary Elizabeth } \\
\text { Cerrutti. }\end{array}$ & RBLA (Belo Horizonte) \\
\hline 7 & 2015 & $\begin{array}{l}\text { O que pensam os } \\
\text { professores sobre seus } \\
\text { alunos: Aspectos } \\
\text { psicossociais de Educação } \\
\text { de Jovens e Adultos }\end{array}$ & $\begin{array}{c}\text { NAIFF, Luciene Alves } \\
\text { Miguez/ NAIFF, Dennis } \\
\text { Giovane Monteiro/ } \\
\text { PEREIRA, Jacqueline Mary } \\
\text { Monteiro/ ÁVILLA, Rapahel } \\
\text { Pereira }\end{array}$ & $\begin{array}{l}\text { Revista Interinstitucional de } \\
\text { Psicologia }\end{array}$ \\
\hline 8 & 2015 & $\begin{array}{l}\text { Aspectos pessoais e } \\
\text { escolares associados à } \\
\text { autoeficácia acadêmica no } \\
\text { Ensino Médio }\end{array}$ & $\begin{array}{l}\text { COUTO,Daniela Guerreiro- } \\
\text { Casanova } \\
\text { DANTAS, Marilda Aparecida } \\
\text { AZZI, Roberta Gurgel }\end{array}$ & $\begin{array}{l}\text { Periódicos Eletronicos em } \\
\text { Psicologia: Psicol. Ensino \& } \\
\text { Form }\end{array}$ \\
\hline 9 & 2015 & $\begin{array}{l}\text { A escola e a semiliberdade: } \\
\text { a importância do diálogo }\end{array}$ & $\begin{array}{c}\text { MOREIRA, Jacqueline de } \\
\text { Oliveira } \\
\text { MELGAÇO, Paula } \\
\text { Albuquerque,Bruna Simões } \\
\text { de } \\
\text { rocha, Bianca Ferreira } \\
\text { RIBEIRO, Ana Carolina } \\
\text { Ferreira }\end{array}$ & Psicologia em Revista - P@psic \\
\hline 10 & 2019 & $\begin{array}{l}\text { As origens emocionais da } \\
\text { evasão: apontamentos } \\
\text { etnográficos a partir da } \\
\text { Educação de Jovens e } \\
\text { Adultos }\end{array}$ & LIMA, Alef de Oliveira & $\begin{array}{c}\text { Horizonte Antropológico (Porto } \\
\text { Alegre) }\end{array}$ \\
\hline
\end{tabular}

Fonte: Elaborado pelos autores (2020).

$\mathrm{Na}$ tabela 2, podem ser observados os objetivos de cada pesquisa, bem como o tipo de estudo e instrumentos de análise.

Tabela 2 - Objetivos e métodos empregados nos artigos selecionados.

\begin{tabular}{cccc}
\hline Id & Objetivo & Tipo de estudo & Instrumentos para análise \\
\hline & $\begin{array}{c}\text { Discutir a escola e seu papel de agente } \\
\text { de inclusão ou exclusão nas memórias de } \\
\text { vida apresentadas. }\end{array}$ & Estudo de Campo & Entrevistas \\
& $\begin{array}{c}\text { vidas } \\
\end{array}$ & &
\end{tabular}


Entender os aspectos psicossociais da

2 educação focada no ensino de jovens e adultos (EJA).
Questionário com questões

fechadas e uma tarefa de evocação livre utilizando como tema indutor o aluno do EJA

Reflexão a respeito dos processos de inclusão e evasão escolar no Ensino

3 Médio sob o enfoque de como Estudo bibliográfico

Entrevistas a motivação pode se associar aos mesmos.

\begin{tabular}{|c|c|c|c|}
\hline 4 & $\begin{array}{l}\text { Analisar as relações entre as variáveis } \\
\text { pessoais e escolares e os níveis de } \\
\text { autoeficácia acadêmica percebidos pelos } \\
\text { estudantes de Ensino Médio. }\end{array}$ & $\begin{array}{l}\text { Estudo de campo } \\
\text { Questionário de } \\
\text { Caracterização e a } \\
\text { Escala de Autoeficácia } \\
\text { Acadêmica para o } \\
\text { Ensino Médio. }\end{array}$ & $\begin{array}{c}\text { Pesquisa descritiva com } \\
\text { delineamento correlacional } \\
\text { multivariado. }\end{array}$ \\
\hline 5 & $\begin{array}{l}\text { Examinar a relação do trabalho precoce } \\
\text { com o processo de escolarização de } \\
\text { crianças e adolescentes, analisando } \\
\text { a subjetividade forjada com o trabalho e } \\
\text { o estudo no processo de escolarização. }\end{array}$ & Estudo de Campo & $\begin{array}{c}\text { Análise documental, } \\
\text { Territorialização e Entrevistas } \\
\text { individuais semiestruturadas }\end{array}$ \\
\hline 6 & $\begin{array}{l}\text { Abordar o questionamento que vem } \\
\text { sendo feito à educação escolar no que se } \\
\text { refere ao seu alto índice de evasão e à } \\
\text { sua participação na contenção da } \\
\text { violência que se tem presenciado no } \\
\text { mundo e na escola. }\end{array}$ & Revisão Bibliográfica & Entrevistas \\
\hline 7 & $\begin{array}{l}\text { A relação do adolescente autor de ato } \\
\text { infracional com o espaço escolar. }\end{array}$ & Revisão Bibliográfica & Teses e artigos \\
\hline 8 & $\begin{array}{l}\text { Explorar as } \\
\text { representações compartilhadas pelos } \\
\text { profissionais da educação quanto à } \\
\text { situação de fracasso dos alunos. }\end{array}$ & Estudo qualitativo & $\begin{array}{c}\text { Sistema conversacional: } \\
\text { Diálogo }\end{array}$ \\
\hline 9 & $\begin{array}{l}\text { Discutir os momentos etnográficos a } \\
\text { partir das origens emocionais da evasão } \\
\text { com possíveis apontamentos da } \\
\text { escolarização tardia dos sujeitos. }\end{array}$ & Estudo de Campo & $\begin{array}{l}\text { Participação das aulas junto } \\
\text { com os alunos }\end{array}$ \\
\hline 10 & $\begin{array}{l}\text { Apontamento de aspectos identitários } \\
\text { das práticas de letramento dos alunos. } \\
\text { Implicações na inserção da cultura escrita } \\
\text { aos movimentos de permanência e } \\
\text { evasão dos sujeitos no sistema escolar. }\end{array}$ & $\begin{array}{l}\text { Avaliação de entrevistas } \\
\text { e notas de campo. }\end{array}$ & $\begin{array}{l}\text { Entrevistas e trabalho de } \\
\text { campo. }\end{array}$ \\
\hline
\end{tabular}

Fonte: Elaborado pelos autores (2020).

Ao serem verificadas as categorias temáticas destes artigos selecionados, $50 \%(n=5)$ abordaram 0 papel e influência da escola no fracasso e evasão de seus alunos, sendo que $1 / 5$ destas pesquisas 
versou sobre a participação da escola na contenção da violência e seu impacto considerável na evasão; $30 \%(n=3)$ enfatizaram o fracasso escolar associado à subjetividade do aluno, destacando as origens emocionais da evasão, o processo de letramento e as implicações na inserção da cultura escrita; $20 \%(n=2)$ tiveram como foco a figura do professor; e $10 \%(n=1)$ observaram a relação do adolescente infrator com o espaço escolar.

A Tabela 3 mostra os participantes de cada pesquisa, as variáveis explanatórias e as teorias que fundamentaram cada estudo nos artigos selecionados.

Tabela 3: Participantes, variáveis explanatórias e teorias que fundamentam as pesquisas selecionadas.

\begin{tabular}{|c|c|c|c|}
\hline Id & Participantes & Variáveis explanatórias & $\begin{array}{l}\text { Teoria/corrente } \\
\text { filosófica }\end{array}$ \\
\hline 1 & $\begin{array}{l}30 \text { mulheres da cidade } \\
\text { do RJ, divididas em dois } \\
\text { grupos de } 15 \text { mães e } 15 \\
\text { filhas, moradoras de } \\
\text { favelas ou invasões }\end{array}$ & $\begin{array}{l}\text { (1) Lembranças da escola; } \\
\text { (2) Lembranças do trabalho na infância e } \\
\text { adolescência; } \\
\text { (3) Possibilidades de mudança de vida; } \\
\text { (4) Arrependimentos. }\end{array}$ & $\begin{array}{l}\text { Teoria das } \\
\text { Representações } \\
\text { Sociais }\end{array}$ \\
\hline 2 & 100 professores do EJA & $\begin{array}{l}\text { Variáveis sociais: } \\
\text { Idade do aluno / Emprego / Desemprego / Baixa } \\
\text { escolarização. }\end{array}$ & $\begin{array}{l}\text { Teoria das } \\
\text { representações } \\
\text { sociais }\end{array}$ \\
\hline 3 & $\begin{array}{l}\text { Paraná: } 26 \text { professores } \\
\text { da educação básica / } \\
\text { Campinas: } 30 \text { alunos do } \\
\text { ensino médio / } \\
\text { Nacional: } 50 \text { mil alunos } \\
\text { e } 7 \text { mil professores }\end{array}$ & $\begin{array}{l}\text { (1) Inclusão de pessoas com necessidades especiais; } \\
\text { (2) Alunos com dificuldades na aprendizagem; } \\
\text { (3) Despreparo do professor em lidar com as } \\
\text { diversidades dos alunos; } \\
\text { (4) Ambiente escolar inadequado às práticas } \\
\text { pedagógicas e de inclusão. }\end{array}$ & $\begin{array}{c}\text { Teoria das } \\
\text { Representações } \\
\text { Sociais }\end{array}$ \\
\hline 4 & $\begin{array}{l}886 \text { estudantes de onze } \\
\text { escolas do Ensino Médio } \\
\text { público paulista. }\end{array}$ & $\begin{array}{l}\text { Variáveis escolares (tipo de escola em que cursou o } \\
\text { Ensino Fundamental, tipo de curso fundamental, } \\
\text { repetência, intenção de concluir o Ensino Médio e } \\
\text { intenção de ingressar no Ensino Superior). } \\
\text { Variáveis pessoais (gênero, idade, estudo do pai, } \\
\text { estudo da mãe, trabalho e horas de trabalho). } \\
\text { Variáveis de níveis de autoeficácia acadêmica }\end{array}$ & $\begin{array}{l}\text { Teoria das } \\
\text { Representações } \\
\text { Sociais }\end{array}$ \\
\hline
\end{tabular}

21 sujeitos

na faixa etária de 10 a

514 anos, dos gêneros masculino e feminino.
(1) Gênero;

(2) Idade;

(3) Escolaridade;

(4) Trabalho; e as perspectivas de futuro;

(6) Processo de escolarização dos trabalhadores precoces.
6 Participação popular
Artigos
Violência na escola.

Renda baixa.

Adolescentes acautelados.

Adolescentes analfabetos.
Teoria das

Representações

Sociais

Teoria das

Representações

Sociais 
Quatro professoras de educação regular de

Formas de organização social. Prática dos profissionais de educação.
Teoria das

Representações

Sociais $\mathrm{ABCD} / \mathrm{SP}$

Estudantes do Ensino

9 Médio de Educação de Jovens e Adultos (EJA). $1^{\circ}$ ao $3^{\circ}$ Colegial

Escola da rede municipal do norte da Ilha do Município de Florianópolis (SC).
(1) Convivência com os alunos;

(2) Convivência com os professores;

(3) Escuta da demanda dos alunos em contestar a falta de interesse do Ensino.
Teoria das

Representações

Etnográficas
10
(1) Convivência com os alunos do EJA;

(2) Verificação dos participantes; dos artefatos; do contexto e do ambiente.
Representações Etnográficas e sua formulação identitária no âmbito da Alfabetização.

Fonte: Elaborado pelos autores (2020).

No que se referem aos participantes, o público-alvo da maior parte dos artigos selecionados foram a escola e os alunos: 3 artigos envolvem os professores, 5 os alunos, 1 a participação popular e 1 a escola em todas as esferas administrativas.

As variáveis explanatórias mais recorrentes foram as pessoais, como gênero, idade, trabalho, escolaridade, estudo do pai ou da mãe e horas de trabalho; e as escolares: tipo de escola que cursou Ensino Fundamental, repetência, intenção de concluir Ensino Médio, dificuldades de aprendizagem, despreparo do professor, ambiente escolar inadequado, práticas dos professores, convivência com alunos e professores, adolescentes analfabetos e escuta da demanda dos alunos.

Variáveis sociais também foram levantadas em dois artigos, como trabalho precoce, desemprego, violência na escola, adolescentes acautelados, possibilidades de mudança de vida, arrependimentos e lembranças das escolas.

Em relação aos dados encontrados nas Tabelas 1, 2, 3 e 4, alguns merecem destaque para a discussão. A questão da violência na escola levanta questionamentos sobre como a escola apenas cumpre sua função educadora e não leva em consideração os fatores psíquicos das relações escolares. No caso dos adolescentes infratores a escola impõe obstáculos, segrega criando barreiras em decorrência do mal-estar em que professores e direção transmitem, ao declararem que esses jovens são os únicos culpados por seu fracasso escolar.

Quanto aos alunos de EJA (Educação de Jovens e Adultos), o principal fator para evasão é o excesso de trabalho, o cansaço e fatores sociais que os obrigam a abandonar a escola. Isto causa traumas que dificilmente serão tratados e favorecem o distanciamento destes alunos da rede educacional.

Face ao exposto fica evidente que a escola é vista como instituição confiável, que favorece aprendizagens, levanta expectativas em relação ao futuro dos alunos, oferece oportunidades e é lembrada com carinho por alunos que abandonam os estudos; no entanto, para o grupo dos menores infratores, é vista como lugar de segregação, o qual não favorece o diálogo entre alunos, professores e direção e possivelmente, neste caso, sejam necessários repensar estratégias e metodologias para atender esta demanda. 
Já em relação às linhas teóricas que fundamentaram estes estudos, $70 \%$ (n-7) dos artigos embasaram-se na Teoria das Representações Sociais, 20\% $(n=2)$ nas Representações Etnográficas e $10 \%(n=1)$ na Psicologia Histórico-cultural de Vygotsky.

Deste modo, a teoria aplicada na maioria dos estudos foi a Teoria das Representações Sociais. Esta teoria surge em 1961 com a publicação da obra "La psychanalyse,son image et son public", traduzida em português para "A psicanálise, sua imagem e seu público", escrita pelo psicólogo social francês Serge Moscovici. Essa teoria emerge como uma crítica à uma forma de pensamento tradicional, presente na América do Norte e Grã - Bretanha, onde se estabelecia separação entre o sujeito e seu contexto social, ou seja, está fundamentada na intrínseca relação que o sujeito estabelece com o meio em que vive, mesmo que inconscientemente. Moscovici (1961) defende a teoria que não existe separação entre o mundo interno do sujeito e o universo externo a este sujeito. Em sua obra, 0 autor explica que as representações sociais são construídas nas interações dos sujeitos, sendo esses, frutos de conhecimentos práticos que são estabelecidos pelo conjunto de ideias da vida cotidiana e construídas nas relações interpessoais. A representação social tem suas características, sendo elas impossíveis de serem dissociadas: uma delas figurativa, que corresponde ao objeto, e outra simbólica, que corresponde ao sentido que o sujeito atribui ao objeto, sendo assim, entende-se que não existe representação sem objeto. Jovchelovitch $(1995$, p. 78$)$ diz que "é através da atividade do sujeito e de sua relação com outros que as representações têm origem, permitindo uma mediação entre o sujeito e o mundo que ele ao mesmo tempo descobre e constrór'.

Ao deparar-se com a gama de possibilidades que podem motivar o fracasso escolar, sabendo que não existe fórmula para alcançar o sucesso no processo de ensino- aprendizagem, é possível, então, entender a relação entre o processo educacional e a citada teoria. No ambiente escolar, lidamos dia a dia com as disparidades e desigualdades sociais, além de saber que os alunos vivem realidades distintas, porém estão submetidos ao mesmo ambiente de vivência e aprendizado. Neste cenário, o ambiente coletivo deve ser o alicerce de um sistema igualitário, onde as possibilidades e oportunidades devem ser as mesmas, independente das escolhas e crenças individuais.

Já na Tabela 4, os principais resultados encontrados nos artigos selecionados focam nos problemas de educação, fatores externos, professores e posicionamento dos alunos.

Tabela 4 - Principais resultados das pesquisas

Id Principais resultados

A instituição escolar e o ato de estudar, de uma maneira geral, representam aspectos positivos vividos

1 no passado e se projetam nos discursos sobre o futuro como possibilidades de mudança de vida. As práticas sociais, por outro lado, expõem rotinas que não incluem a escola.

2 O fracasso escolar irá desencadear um problema futuro: a dificuldade de inserção no mercado de trabalho / Necessário uma pedagogia voltada para o ensino de adultos.

O Ensino Médio possui características singulares no processo de escolarização do estudante no Brasil. Sabendo da amplitude que a variável motivação pode atingir quanto ao fomento de níveis de discussão

3 na educação em geral, este estudo se restringiu a um pequeno recorte focado nos processos de inclusão e evasão no contexto escolar. O aluno do ensino médio necessita um olhar centrado nas suas especificidades, visando a manutenção da escolarização e diminuição da evasão 
Os dados obtidos, quando analisados por meio da análise descritiva, revelaram que os estudantes participantes desta pesquisa percebem-se moderadamente $(n=886 ; M=5,06 ; D P=0,97)$ capazes de realizar com êxito as atividades inerentes ao aprender.

Dentre as variáveis pessoais e escolares investigadas, poucas são as que se relacionam significativamente com os níveis de autoeficácia acadêmica dos estudantes São elas: gênero, idade, estudo do pai, intenção de ingressar no Ensino Superior e repetência de alguma série. Gênero e intenção de ingressar no Ensino Superior mostraram-se como as mais importantes variáveis, de acordo com a análise de regressão logística multivariada realizada. O gênero dos estudantes mostrou ser uma variável importante para todas as dimensões da autoeficácia acadêmica.

5 O trabalho acarreta perdas a nível pessoal de desenvolvimento (educacional, físico, lúdico e psicológico) e no nível social (violação dos direitos sociais humanos assegurados pela legislação).

6 O resultado revelou que a principal preocupação é com a educação e que a escola é considerada como um lugar de violência, com grupos impondo-se sobre outros.

7 Foi possível verificar que o processo educativo coloca obstáculos tanto para o aluno, em especial o adolescente em conflito com a lei, com para a instituição escolar.

A "situação de fracasso escolar tem raízes externas às relações escolares". A esfera subjetiva que

8 ampara as ações dos professores em relação a determinados alunos, marginaliza o processo de escolarização, predestinando a todos ao fracasso escolar.

A evasão dos colegas faz que os alunos presentes pensem sobre suas motivações atuais, dando importância as aventuras existenciais do outro. O desanimo e o cansaço dos evasores são a causa das rotinas extenuantes. $O$ retorno dos evasores marcam a necessidade de se subjetivarem. Esta volta do evasor denota um novo entendimento existencial de dentro para fora.

Formulação da identidade institucional do aluno de forma precária. Pecado da agência educadora em ter um repasse da aprendizagem do letramento de forma autônoma e descomprometida com os fluxos de aprendizagem do educando. Interesse da gestão em resgatar os evasores. Justificativa da evasão por motivos de natureza laboral ou de saúde.

Fonte: Elaborado pelos autores (2020).

Os principais resultados demonstram que a instituição escolar projeta aspectos positivos para o futuro, alguns alunos apostam na escola como possibilidade de ingresso no Ensino Superior, porém práticas sociais anulam o aluno e não incluem a escola. O excesso de trabalho e falta de tempo para se dedicar aos estudos afetam o desenvolvimento tanto educacional quanto psicológico do aluno.

No que diz respeito à evasão escolar, pode-se inferir que as seguintes variáveis estão associadas a este fenômeno: falta de investimento no aluno por parte das escolas, ausência de um olhar mais específico para as dificuldades de aprendizagens, relação professor-aluno comprometida (os quais, muitas vezes marginalizam os alunos), desânimo, cansaço e precarização da identidade dos alunos.

Por último, na Tabela 5, podem-se observar as conclusões/contribuições para a compreensão sobre o fracasso escolar no Ensino Médio encontradas nos artigos selecionados.

Tabela 5 - Conclusões sobre fracasso escolar

Id Conclusões sobre fracasso escolar

O fracasso escolar ocorre devido ao cotidiano de vulnerabilidade a que estão submetidas as entrevistadas

1 por gerações e a uma provável inadequação da proposta pedagógica da escola pública brasileira no que tange ao combate da evasão escolar. 
- Parte das causas do fracasso escolar tem raízes no próprio sistema de ensino;

2 - Deficiência na formação inicial e formação continuado dos docentes;

- Avaliações equivocadas.

Em relação às estratégias para prevenção da evasão escolar, sabendo que o processo envolvendo a

3 mesma não se resume ao momento em que o aluno deixa a escola, as estratégias de prevenção devem começar cedo junto aos alunos, pois as atitudes e comportamentos problemáticos que podem levá-los à evasão também começam geralmente cedo.

Pelo exposto, pode-se perceber que a crença de autoeficácia acadêmica pode ser um importante contributo para se melhorar o desempenho estudantil e reduzir o abandono escolar, temas correntes na

4 realidade brasileira. Desse modo, ampliar a compreensão que se tem sobre a contribuição de aspectos pessoais e escolares para a construção da autoeficácia acadêmica coloca-se como um problema relevante, porquanto o conhecimento a ser produzido pode auxiliar no desenvolvimento de ações e políticas educacionais.

O trabalho precoce restringe as chances de aprender, de estudar da criança e adolescente e com isso,

5 de ter uma formação melhor, a qual lhes permitiria não apenas inserir-se em atividades profissionais socialmente valorizadas e bem remuneradas no futuro, mas sobretudo lhes asseguraria uma condição cidadã mais digna e socialmente participativa.

Uma análise de como a educação não vem levando em conta o que ultrapassa a transmissão do conhecimento, ou seja, o espaço psíquico presente nas relações escolares. Apontamos também como os impasses da educação estão intimamente vinculados aos impasses de nossa sociedade e às questões do 6 equacionamento das forças pulsionais. No cenário de crise de autoridades, de falta de referências e de valores, têm-se as condições psicológicas que favorecem a passagem ao ato, o aumento da violência e a falta de entusiasmo com a aprendizagem escolar. A escola está inserida numa sociedade em que o individualismo coloca em último plano a solidariedade; em que não se tem tolerância à frustração, perseguindo-se, ao contrário, a busca imediata de satisfação.

As questões sociais, ligadas às dificuldades na comunidade ("guerras" na comunidade), conflitos com

7 professores e coordenação, desmotivação e, ou, falta de tempo, uma vez que muitos precisam trabalhar foram as principais variáveis identificadas associadas a este fenômeno.

A escola, mesmo que seja considerada fundamental para alguns adolescentes, pode se tornar, de certa

8 forma, inacessível e segregacionista, em razão do mal-estar dos professores e da direção, que geralmente consideram esses jovens os únicos responsáveis pelo seu fracasso na escola, seja pela via da expulsão, da evasão ou da repetência.

As inúmeras topografias sentimentais dos evasores canalizam diversos motivos, sociais; emocionais e econômicos como válvula de evasão. $\mathrm{O}$ fracasso escolar atinge, o fracassado e o alunato presente. A volta dos desertores (alutado desistente) ressignifica a escolarização tardia, como um novo modo do sujeito perceber-se existencialmente de dentro para fora. Isso promove uma nova interpretação do fracasso escolar e uma transformação das torções traumáticas que as atitudes dos desertores lhe causaram.

Evasão como um fenômeno inserido em um construto social. Por vezes o sistema escolar favorece um processo de exclusão quando evidencia o domínio dos usos da escrita requeridos pela escolar que não convergem com os usos realizados pelos alunos em âmbito social Necessidade da escola em se horizontalizar as práticas do uso da língua.

Fonte: Elaborado pelos autores (2020).

Esta revisão demonstrou em suas conclusões que a evasão escolar ocorre na maioria das vezes pelos seguintes motivos: vulnerabilidade, falta de adequação das propostas pedagógicas a realidade dos estudantes; sistema educacional que favorece a exclusão; falta de políticas públicas. Os fatores sociais também foram apontados como principais agentes de evasão escolar, pois o trabalho precoce dificulta a aprendizagem do aluno tirando-lhe a oportunidade de um futuro melhor. 
Os fatores sociais são evidenciados através da carga de trabalho, a falta de oportunidade para estudar em idade apropriada (geralmente por conta do trabalho precoce) e o cansaço, pois alunos que trabalham não conseguem acompanhar a demanda exaustiva que o sistema de ensino proporciona. Sendo assim, podemos elencar que políticas públicas são necessárias para solucionar o fenômeno da evasão escolar deste público específico. A culpa não está apenas na escola e nos professores, mas sim nas condições de vidas precárias que a classe trabalhadora e, consequentemente a menos favorecida, enfrenta.

\section{CONSIDERAÇÕES FINAIS}

A revisão realizada sobre o fracasso escolar e evasão no Ensino Médio no contexto brasileiro demonstrou, de um modo geral, que este é um fenômeno que envolve as esferas sociais, pessoais, técnicas, institucional, política e psíquica. Possibilitou ainda entender como o fenômeno da evasão escolar tem-se comportado frente as diferentes situações, não existindo assim um percurso para o sucesso e tampouco uma causa para o insucesso. Condições sócio emocionais dos alunos; cognitivas; psicológicas; familiar; precarização do ensino; problemas de estrutura escolar; desvalorização da figura docente são algumas variáveis que comumente rodeiam os motivos da evasão escolar.

Quando Angelucci (2004) trata o fracasso escolar como uma questão política, coloca-nos posteriormente a refletir como as relações socioemocionais e etnográficas institucionais seccionam o modo de vida dos alunos viabilizando alguns e destituindo outros. Quando se tem meios de vivenciar relações familiares estruturantes somada ao âmbito antropológico de escola instigante e motivante ao aluno, reúne-se varáveis politicamente favoráveis a extinção da evasão escolar. Quando o ato político das variáveis não se colabora, não se conversam e se confundem entre si, reúnem uma situação estrutural politicamente antropológica que naturalmente destitui os organismos que positivam as variáveis que conversam entre si. Portanto, este estrato político que relaciona as variáveis e acompanha o processo do sujeito educando é um resultado que limita os seres ou institui os seres ao progresso.

Sabe-se que as bases de publicação dos referidos artigos deste trabalho, comumente está a frequentar os anais da psicologia. Esta constatação coloca-nos a entender a evasão escolar dentro da trama humana, analisando com neutralidade, entendendo a perspicácia humana da sociedade de poder e os entraves que este resultado político pode deprimir o sujeito. É bom saber que o viés analítico nos coloca a pensar juntamente com os instrumentos que ora estruturam a ciência dos artigos. O fato é que confluem, ou melhor, temos diversas ciências reunidas aqui que se prestam a lisura dos apontamentos sobre a evasão escolar.

É muito perigoso a agência escolar destituir-se de si os cuidados para com a subjetividade de seus alunos, não atrelando ensino-aprendizagem ao histórico subjetivo. Os processos mentais se executam neste espaço de vivência subjetiva. Portanto, a conciliação destes dois setores de investidas ao alunato, é importante fator para a confluência das variáveis rumo a destituição de fatores que colaborem com a evasão escolar.

Enfim, temos um construto, ou melhor, uma edição aglomerada de variáveis que auxiliam no deslocamento do sujeito rumo ao progresso ou a evasão escolar. Quando determinamos ser preocupante a evasão escolar, subentende que dizemos que a escola é muito importante para a inserção no mundo. 


\section{REFERÊNCIAS}

ANGELUCCI, Carla Biancha; KALMUS, Jaqueline; PAPARELLI, Renata; PATTO, Maria Helena Souza. O estado da arte da pesquisa sobre o fracasso escolar (1991-2002): um estudo introdutório.?Educ. Pesqui.,? São Paulo,? v. 30,?n. 1,?p. 51-72,? Abril? 2004

BARDIN, Laurence. Análise de conteúdo. Lisboa: Edições, 2009. BOURDIEU, Pierre. 0 poder simbólico. Rio de Janeiro: Bertrand Brasil, 2000.

FARR, Robert. Representações Sociais: a teoria e sua história. Sociedade e Estado, Brasília, v. 24, n. 3, p. 645-652, set./dez. 2009.

FAUBERT, Brenton. (2012). A Literature Review of School Practices to Overcome School Failure, OECD. Education, Working Papers, No. 68, OECD Publishing. Retrieved March 27, 2013.

FORGIARINI, Solange Aparecida Bianchini; SILVA, João Carlos da. Escola pública: fracasso escolar numa perspectiva histórica. Simpósio de Educação-XIX Semana de Educação-A formação de Professores no Contexto da Pedagogia Histórico-Crítica, v. 35, 2007.

GOMES, Claudia; SOUZA, Vera Lucia Trevisan de. Fracassos, representações e exclusões no processo de permanência na escola. Rev. psicopedag., São Paulo, v. 26, n. 79, p. 41-47, 2009.

GUERREIRO-CASANOVA, Daniela Couto; DANTAS, Marilda Aparecida; AZZI, Roberta Gurgel. Aspectos pessoais e escolares associados à autoeficácia acadêmica no Ensino Médio. Psicol. Ensino \& Form., Brasília, v. 6, n. 1, p. 72-94, 2015.

GUIMARÃES, Marisa Siggelkow. A educação, a sublimação e os ideais. Trivium-Estudos Interdisciplinares, v. 3, n. 1, p. 55-67, 2011.

JOVCHELOVITCH, Sandra. Textos em Representações Sociais. Petrópolis: Vozes, 1995.

LIMA, Alef de Oliveira. As origens emocionais da evasão: apontamentos etnográficos a partir da Educação de Jovens e Adultos. Horiz. antropol., Porto Alegre, v. 25, n. 54, p. 253-272, Aug. 2019.

MENDES, Marcelo Simões. Da inclusão à evasão escolar: o papel da motivação no ensino médio. Estud. psicol. (Campinas), Campinas, v. 30, n. 2, p. 261-265, June 2013.

MOREIRA, Jacqueline de Oliveira; MELGAÇO, Paula; ALBUQUERQUE, Bruna Simões de; ROCHA, Bianca Ferreira; RIBEIRO, Ana Carolina Ferreira. A escola e a semiliberdade: a importância do diálogo. Psicol. rev. (Belo Horizonte), Belo Horizonte, v. 21, n. 1, p. 50-65, jan. 2015.

MOROSINI, Marilia Costa. Estado de conhecimento e questões do campo científico. Educação (UFSM), v. 40, n. 1, p. 101-116, 2015.

MOSCOVICI, Serge. La psychanalyse: son image et son public, Paris: PUF, 1961.

NAIFF, Luciene Alves Miguez; NAIFF, Denis Giovani Monteiro; PEREIRA, Jacqueline Mary Monteiro; ÁVILA, Raphael Ferreira de. O que pensam os professores sobre seus alunos: aspectos psicossociais da Educação de Jovens e Adultos. Gerais, Rev. Interinst. Psicol., Juiz de fora, v. 8, n. 1, p. 1932, jun. 2015.

NAIFF, Luciene Alves Miguez; DE SÁ, Celso Pereira; NAIFF, Denis Giovanni Monteiro. Preciso estudar para ser alguém: memória e representações sociais da educação escolar. Paidéia (Ribeirão Preto), v. 18, n. 39, p. 125-138, 2008. 
PATTO, Maria Helena Souza. O fracasso escolar como objeto de estudo: anotações sobre as características. Cadernos de pesquisa, n. 65, p. 72-77, 1988.

PEDRALLI, Rosângela; CERUTTI-RIZZATTI, Mary Elizabeth. Evasão escolar na educação de jovens e adultos: problematizando o fenômeno com enfoque na cultura escrita. Rev. bras. linguist. apl., Belo Horizonte, v. 13, n. 3, p. 771-788, Set. 2013.

SÁ, Celso Pereira. Representações sociais: o conceito e o estado atual da teoria. O conhecimento no cotidiano. São Paulo: Brasiliense, p. 19-45, 1993.

SARAIVA, Adriana. Síntese de Indicadores Sociais: Abandono escolar é oito vezes maior entre jovens de famílias mais pobres. Estatísticas Sociais, 2019.

SOUSA, Olívia Maria Costa Grangeiro de; ALBERTO, Maria de Fátima Pereira. Trabalho precoce e processo de escolarização de crianças e adolescentes. Psicol. estud., Maringá, v. 13, n. 4, p. 713722, Dez. 2008.

SIMÕES, Renata Duarte. Evasão e permanência na educação de jovens e adultos: o papel da escola nesses processos. Belo Horizonte: Pensar a Educação em pauta: Um Jornal para a Educação Brasileira, 2017. 